East African Medical Journal Vol. 81 No. 9 September 2004

INTUSSUSCEPTION IN CHILDREN SEEN AT MUHIMBILI NATIONAL HOSPITAL, DAR ES SALAAM

PMR Carneiro, MD, MMed, Dipl. Paed. Surg, and D.M. Kisusi, MD, Paediatric Surgery Unit, Department of Surgery, Muhimbili University College of Health Sciences, P. O. Box 65451, Dar es Salaam, Tanzania.

Request for reprints to: Prof. P. M. R. Carneiro, Paediatric Surgery Unit, Department of Surgery, Muhimbili University College of Health Sciences, P. O. Box 65451, Dar es Salaani, Tanzania

\title{
INTUSSUSCEPTION IN CHILDREN SEEN AT MUHIMBILI NATIONAL HOSPITAL, DAR ES SALAAM
}

\section{P. M. R. CARNEIRO and D. M. KISUSI}

\begin{abstract}
Objective: To review infants and children with intussusception and assess its magnitude of concern and any seasonal variation in our environment.

Design: A retrospective study.

Setting: Muhimbili National Hospital general paediatric and surgical wards from January 2000 to February 2004.

Methodology: The charts of all infants and children up to the age of 10 years diagnosed to have intussusception were reviewed. Demographic factors evaluated included age, incidence in up to one-year olds, sex, month of presentation to assess seasonal variation, clinical features, methods of diagnosis and management, aetiology and any recurrence. Results: Twenty eight children were diagnosed to have intussusception. Sixteen were males and 12 females (M:F=1 .3:1). Of these, 21(75\%) were infants (up to the age of one year), nine were boys and 12 were girls( M.F=l:1.3). Incidence rate in this age group was approximately 1: 7557. Most cases presented in January-March(39.3\%) and July to September $(39.3 \%)$. No case was seen in the month of April during the 4-year period. Except in 2002, there has been a male preponderance. The aetiology was mainly idiopathic $(85.7 \%)$, there were three cases suspected to be due to mesenteric adenitis and one case of intraluminal haemangioma. There were two recurrent cases, one was within a week with no known aetiology. All patients presented with vomiting and abdominal pain/distension. Preceding gastro-enteritis was common. The majority of the cases, $17(60.7 \%)$ presented with the classic triad of vomiting, rectal bleeding and abdominal pain/distension. Abdominal mass was often difficult to palpate due to gross or tense abdomen and was only palpated in four cases(14.3\%). Air or barium reduction is not done at our institution due to apart from lack of facilities, majority of the children present late, $>\mathbf{4 8}$ hours from the onset of symptoms and diagnosis was mainly based on clinical symptoms and signs of intestinal obstruction and confirmed with presence of multiple fluid levels on a plain erect abdominal $X$-ray. All children were then managed by surgery, 11(39.3\%) underwent bowel resection. Histopathology reports of those available did not show cause of intussusception. Seven patients died postoperatively, hospital mortality of $25 \%$.

Conclusion: The approximate incidence of intussusception in less than one-year olds is 1:7557 in Dar es Salaam. It is a concern in our environment causing considerable morbidity and mortality due to late presentation and efforts should be made to improve sanitation and hygiene, referring health facilities, socio-economic factors and probably look into ways of preventing the problem occurring. Seasonal variation was seen, most cases $(\mathbf{7 8 . 6 \%}$ ) presenting in the dry season when there is shortage of water in the city.
\end{abstract}

\section{INTRODUCTION}

Intussusception is a fairly common cause of intestinal obstruction in infancy and children seen worldwide(1,2). In our region in Africa, however, few studies have been done in the last decade which show varying patterns of prevalence. In a review in Harare, Zimbabwe(3), it was frequently seen with $75 \%$ of the children below 12 months of age. A study in Mozambique also revealed $74 \%$ of cases presented in infancy(4). In Zambia, two reviews of paediatric surgical admissions did not reveal intussusception to be a frequent cause. In Lusaka(5), it was not seen among the seven common causes of admission whereas in Chingola(6), worm infestation (59.4\%) and necrotising enterocolitis $(21.8 \%)$ were the common causes of intestinal obstruction in children In yeneral reviews of commonest causes of intestinal obstruction in all age groups, intussusception appeared high on the list in two studies in our region, third in a Maputo study(4) and 
fourth in a Central Provincial hospital in Kenya(7). Male preponderance has been reported in two studies in our region $(3,4)$ and late presentation $(>48$ hours after onset of symptoms) is common resulting in high morbidity and mortality(3). Ileo-ileal(4) and ileo-colic(3) intussusceptions are the common presentations in infancy but the aetiology is often unknown, the recent report of the rotavirus vaccine being associated with development of intussusception is controversial(8). There has been no recent study on intussusception in children in Tanzania to assess its magnitude. This review is not exhaustive but attempts to give an overview of the situation seen in our largest referral National Consultant Hospital.

\section{MATERIALS AND METHODS}

This was a retrospective study whereby the charts of all children up to the age of 10 years presenting clinically and diagnosed to have intussusception were reviewed. Children above 10 years with surgical problems are admitted in the adult surgical wards and therefore excluded from the study. The review period included 50 months, from January 2000 to February 2004. All children were admitted either in the general or surgical paediatric wards of Muhimbili National Hospital. Demographic features evaluated included age, sex, month of presentation to establish any seasonal variation, presenting clinical symptoms and signs, methods of diagnosis, treatment modality, known aetiology seen at surgery, outcome (discharged home or died) and any recurrent cases. The approximate incidence rate of intussusception in under one-year old infants was calculated by obtaining the number of infants $0-11$ months old in referral area in one year and dividing by number of all intussusception cases among infants $0-11$ months that presented at Muhimbili National Hospital in that year.

\section{RESULTS}

A total of 28 children were diagnosed to have intussusception between January 2000 and February 2004 (period of 50 months). Sixteen were males and 12 females (M:F=1.3:1). Of these, $21(75.0 \%)$ were infants (up to the age of one year), nine were boys and 12 girls ( $M: F=1: 1.3$ ). Table 1 shows the ageyear distribution of intussusception (IS) cases seen. 60,453 infants (0-11 months) were living in Dar-esSalaam in 2002(9). Eight infants presented with intussusception in the same year giving an approximate incidence of 1:7557. Figure 1 shows seasonality of intussusception. There were two peaks, majority of cases appeared in January-March(39.3\%) and in JulySeptember(39.3\%). No case was seen in the month of April during the 4-year period.
Table 2 shows some of the characteristics of the intussusception cases that were seen. Except in 2002 there has been a male preponderance. The aetiology in the majority of the cases was idiopathic, there were three cases suspected to be due to mesenteric adenitis and one case of intraluminal haemangioma. There were two recurrent cases, one was within a week with no known aetiology,

Table 3 shows clinical signs and symptoms of confirmed intussusception cases. All presented with vomiting and abdominal pain/distension. The majority, 17 cases $(60.7 \%)$ presented with the classic triad of vomiting, rectal bleeding and abdominal pain/distension. Abdominal mass was often difficult to palpate due to gross or tense abdomen and was only palpated in four cases $(14.3 \%)$. Table 4 shows methods of diagnosis, treatment and outcome of confirmed IS cases. Air or barium reduction is not done at our institution due to apart from lack of facilities, majority of the children presented late in poor general condition, $>48$ hours from the onset of symptoms and diagnosis was mainiy based on clinical symptoms and signs of intestinal obstruction and confirmed with presence of multiple fluid levels on a plain erect abdominal X-ray. All children were then managed by surgery following adequate resuscitation, $11(39.3 \%)$ underwent resection of bowel followed by primary anastomosis: either due to failed intraoperative reduction or gangrenous intussusceptum. Of these six patients died $(54.5 \%)$. Histopathology reports of those available did not establish cause of intussusception. No patient was recorded to have died before surgery. Seven patients died postoperatively, mortality was $25 \%$.

\section{Figure 1}

Seasonality of intussusception in children seen at Muhimbili National Hospital, Tanzania

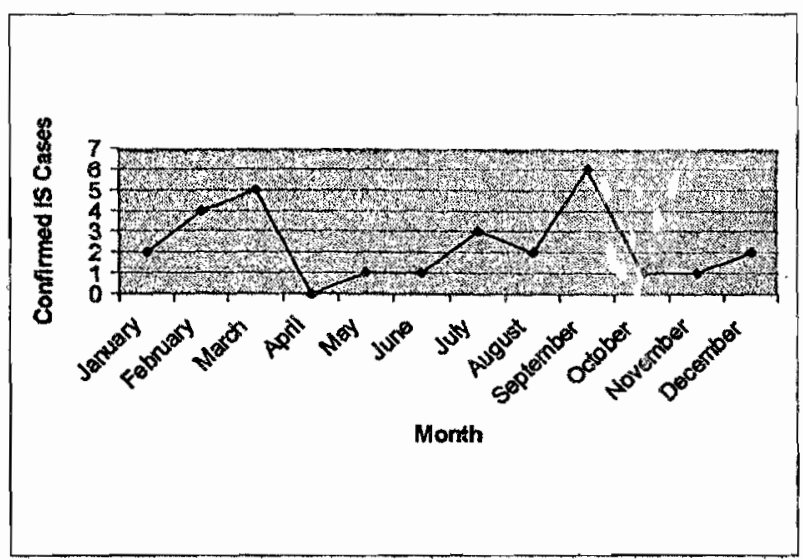


Table 1

Age-year distribution of intussusception cases in Muhimbili National Hospital

\begin{tabular}{|c|c|c|c|c|c|c|}
\hline Age/year & 2000 & 2001 & 2002 & 2003 & Up to Feb 2004 & Total \\
\hline $0-11$ months & 3 & 5 & 8 & 4 & 1 & 21 \\
\hline $1-4$ years & 0 & 2 & 0 & 2 & 0 & 4 \\
\hline $5-10$ years & 1 & 0 & 1 & 1 & 0 & 3 \\
\hline Total & 4 & 7 & 9 & 7 & 1 & 28 \\
\hline
\end{tabular}

Table 2

Characteristics of intussusception cases

\begin{tabular}{lllllll}
\hline Variable & 2000 & 2001 & 2002 & 2003 & Up to Feb 2004 & Total \\
\hline No. & 4 & 7 & 9 & 7 & 1 & 28 \\
No. (\%) Male & $3(75)$ & $4(57.1)$ & $3(33.3)$ & $6(85.7)$ & 0 & $16(57.1)$ \\
Known aetiology & 1 & 0 & 2 & 1 & 0 & 4 \\
Mesenteric adenitis & 1 & & 1 & 1 & 3 \\
Intraluminal Haemangioma & & 1 & 1 & & 1 & 1 \\
No. (\%) recurrent cases & & & & & 1 \\
\hline
\end{tabular}

Table 3

Clinical signs and symptoms of confirmed IS cases in Muhimbili National Hospital

\begin{tabular}{llll}
\hline Sign/Symptom & $\begin{array}{l}0-4 \text { years } \\
\text { No. }(\%)\end{array}$ & $\begin{array}{l}\text { 5-10 years } \\
\text { No. }(\%)\end{array}$ & $\begin{array}{l}\text { Total } \\
\text { No. }(\%)\end{array}$ \\
\hline Abdominal pain/distension & $25(100)$ & $3(100)$ & $28(100)$ \\
Vomiting & $25(100)$ & $3(100)$ & $28(100)$ \\
Rectal bleeding bloody stool & $15(60)$ & $2(66.7)$ & $17(60.7)$ \\
Diarrhoea & $14(56.0)$ & $1(33.3)$ & $15(53.6)$ \\
Constipation & $6(24)$ & $2(66.7)$ & $8(28.6)$ \\
Fever & $4(16)$ & $1(33.3)$ & $5(17.9)$ \\
Lethargy & $22(88)$ & $3(100)$ & $25(89.3)$ \\
Malnutrition & $13(52)$ & $1(33.3)$ & $4(14.3)$ \\
Abdominal mass & $3(12)$ & $1(33.3)$ & $4(14.3)$ \\
Classic triad (vomiting rectal bleeding, & $15(60)$ & $2(66.7)$ & $17(60.7)$ \\
and abnominal pain/distension) & & &
\end{tabular}

\section{Table 4}

Methods of diagnosis, treatment, and outcome of confirmed IS cases in Muhimbili National Hospital

\begin{tabular}{|c|c|c|}
\hline & & No. (\%) \\
\hline Diagnosis & $\begin{array}{l}\text { Clinical signs and symptoms only } \\
\text { Air enema } \\
\text { Barium enema } \\
\text { Ultrasound } \\
\text { Surgery only } \\
\text { Autopsy } \\
\text { Other (please give details) }\end{array}$ & $\begin{array}{l}28(82.1) \\
0 \\
0 \\
2(7.1) \\
3(10.7) \\
0 \\
0\end{array}$ \\
\hline Treatment & $\begin{array}{l}\text { Surgical Managements } \\
\text { - attempted reduction intra-operatively } \\
\text { successfull } \\
\text { Gangrenous bowel } \\
\text { Bowel resection } \\
\text { Discharged } \\
\text { Died }\end{array}$ & $\begin{array}{l}28(100) \\
25 \\
17(68) \\
3 \\
17(39.3) \\
21(75) \\
7(25) \\
\end{array}$ \\
\hline
\end{tabular}




\section{DISCUSSION}

This review reveals an average of seven cases of intussusception were seen in a year at our institution, however, due to poor records this may be an underestimate and a prospective study would be appropriate. However, Shija in 1980(10) reported on 12 consecutive cases seen over a two year period also in this institution and noted intussusception to be the commonest cause of intestinal obstruction in children(11). The Harare review(2) between 1991 and 1996 showed an average of 10 cases per year. The majority $(75.0 \%)$ were infants under one year of age as reported by other studies in our region $(3,4)$, however, contrary to the Harare(3) review, there was a slight female preponderance in this age group. There was a slight male preponderance when all ages of children were taken into consideration as was also seen in the Maputo study(4).

The aetiology in children remains a dilemma as it is largely idiopathic(9) as was also seen in this study and a recent one in Kano, Nigeria(1). Scarcity of water in the city in the dry season in January-March and JulySeptember may lead to increased diarrhoea cases with possible increased incidence of intussusception cases. Most of our infants had preceding gastro-enteritis and were often admitted through the gastro-enteritis ward as was also noted in Shija's review(10) but the latter documented that there was no seasonal variation. A recent study from Southern India(2) revealed intussusception in children had no association with diarrhoeal disease or oral poliovirus vaccine immunization. However, intestinal intussusception was found to be associated with adenovirus infection in a study involving Mexican children(12) and probably may be the cause of mesenteric adenitis that were seen in the three children in this review. Majority present late as was also noted by Shija(10) and the Harare study(3) causing increased morbidity and mortality, this review revealed a high hospital mortality of $25 \%$, six of the seven cases were infants. Late presentation also accounted for the high rate of bowel resection (39.3\%), of these six cases (54.5\%) died. Due to late presentation, all patients presented with classical symptoms and signs of acute intestinal obstruction usually confirmed by an erect abdominal X-ray which showed multiple fluid levels. The passage of blood in stools and palpation of a mass especially in infants contributed highly to clinically suspect the diagnosis of intussusception.
Despite lack of facilities for air or barium reduction, most of our infants would not qualify to attempt such treatment and all were operated on after resuscitation. In all infants with fever, gangrenous intussusceptum was encountered intra-operatively. There were two cases of recurrence, but follow-up period was short to make any conclusive observation. In conclusion, this study reveals that intussusception in children is a concern in our environment causing considerable morbidity and mortality due to late presentation and efforts should be made to improve sanitation and hygiene, referring health center facilities and probably explore ways of preventing the problem occurring. Majority of the cases $(78.6 \%)$ presented in the dry season. The incidence of intussusception in less than one-year olds is approximately 1:7557.

\section{REFERENCES}

1. Edino, S.T., Ochicha, O., Mohammed, A.Z. and Anumah, M. Intussusception in Kano: a 5 year analysis of pattern, morbidity and mortality. Niger J. Med. 2003; 12:221-224.

2. Raman, T., Mukhopadhyaya, A., Eapen, C.E., et al. Intussusception in southern Indian children: lack of association with diarrheal disease and oral polio vaccine immunization. Indian J. Gastroenterol. 2003; 22:82-84.

3. Mbuwayesango, B. Intussusception in children in Harare. East and Central African J. Surg. 1997; 3:66.

4. Garrido, P.I. Intestinal Obstruction in Maputo. Proceedings of the Association of Surgeons of East Africa. 1992; 15:8084.

5. Mbewe, A.L. Patterns of paediatric surgical admissions at the University Teaching Hospital, Lusaka. East and Central African J. Surg. 1995; 1:102.

6. Mugala, D. Intestinal obstruction in children in Chingola. East and Central African. J. Surg. 1997; 3:81.

7. Muyembe, V.M. and Suleman, N. Intestinal obstruction at a provincial hospital in Kenya. East Afr. Med. J. 2000; 77:440-443.

8. Dennehy, P.H. and Bresee, J.S. Rotavirus vaccine and intussusception. Where do we go from here? Infect. Dis. Clin. North Amer. 2001; 15:189-207.

9. Population and Housing Census 2002 Vol. 2, Age and Sex distribution. Central Census Office, National Bureau of Statistics, President's Office, Planning and Privatisation. Published September 2003, pg 125.

10. Shija, J.K. Childhood intussusception in Dar-es-Salaam. The proceedings of the Association of Surgeons of East Africa. 1980; 3:182-184.

11. Shija, J.K. and Mlay, S.M. Intestinal obstruction in infancy and chilhood. The proceedings of the Association of Surgeons of East Africa 1980; 3:180-181.

12. Guarner, J., de Leon-Bojorge, B., Lopez-Corella, et al. Intestinal intussusception associated with adenovirus infection in Mexican children. Amer. J. Clin. Pathol. 2003; 120:845-850. 